\title{
Gonadal suppression by a GnRH analogue does not alter somatic growth in rats with complete $\mathrm{GH}$ deficiency
}

\author{
E Ogawa, B H Breier ${ }^{1}$, I Fujiwara and $\mathrm{K}$ linuma \\ Department of Pediatrics, Tohoku University School of Medicine, 1-1 Seiryo-machi, Aoba-ku, Sendai, 980-8574, Japan \\ ${ }^{1}$ Research Centre for Developmental Medicine and Biology, Faculty of Medicine and Health Science, University of Auckland, Private Bag 92019, Auckland, \\ New Zealand \\ (Requests for offprints should be addressed to E Ogawa; Email: eogawa@ped.med.tohoku.ac.jp)
}

\begin{abstract}
Sexual dimorphism of somatic growth in rats appears to reflect differing actions of sex steroids. However, mechanisms of gonadal steroid effects on the somatotropic axis are incompletely understood. To evaluate whether GH is involved in the effects of long-term gonadal suppression on somatic growth in rats, a $\mathrm{GnRH}$ agonistic analogue (GnRHa) was administered to normal Sprague-Dawley rats (controls) and to a strain of rats with complete growth hormone deficiency (GHD; $n=4-6$ in each group). Subcutaneous injection of $\mathrm{GnRHa}(2 \mathrm{mg} / \mathrm{kg})$ or saline were given within $48 \mathrm{~h}$ after birth and repeated every 3 weeks. GnRHa treatment significantly reduced serum gonadal steroid levels in rats of both sexes with small testes in males and impaired development of internal genitalia in females. GnRHa-treated control females became significantly heavier $(P<0 \cdot 01$ ANOVA for repeated measures) than
\end{abstract}

saline-treated rats beginning at 8 weeks. However, female GHD rats with GnRHa treatment did not differ in body weight from rats receiving saline. In male rats, GnRHa treatment did not change body weight in either control or GHD rats. Serum IGF-I concentrations did not differ between treatment groups in GHD and control rats of either sex. Hepatic GH binding was reduced significantly by GnRHa treatment in female control rats $(P<0 \cdot 01)$, but not in female GHD rats. These data suggest that sexual dimorphism in body size and its modulation by estrogens are independent of circulating IGF-I levels suggesting non-endocrine IGF-I-mediated mechanisms, and that $\mathrm{GH}$-induced somatic growth is modulated by estrogens, but not androgens, in rats.

Journal of Endocrinology (2000) 166, 355-361

\section{Introduction}

Interactions between the somatotropic and the gonadotropic axes play important roles in mammalian somatic growth. Manipulation of gonadal steroid secretory status clearly alters somatic growth in rodents (Jansson et al. 1985, Wehrenberg \& Giustina 1992). However, the precise mechanisms by which gonadal steroids affect the somatotropic axis are not fully understood.

In female rats elimination of estrogens by ovariectomy results in exaggerated growth, while administration of estradiol $\left(E_{2}\right)$ inhibits somatic growth (Jansson et al. 1985). In addition, ovariectomy reduces circulating levels of growth hormone $(\mathrm{GH})$, while $\mathrm{E}_{2}$ administration increases mean GH levels (Carlsson et al. 1987, Borski et al. 1996). In contrast, circulating levels of insulin-like growth factor-I (IGF-I) increase after ovariectomy and decrease with $\mathrm{E}_{2}$ administration (Handelsman et al. 1987, Borski et al. 1996). Furthermore, GH binding in liver is decreased by ovariectomy (Carmignac et al. 1993). Thus, elimination of estrogens in female rats is associated with enhanced growth, low GH, high IGF-I concentrations, and decreased hepatic GH binding. These paradoxical links between growth, GH and IGF-I led to a hypothesis that estrogen action on the somatotropic axis was mediated by inhibition of IGF-I production in the liver or elsewhere (Borski et al. 1996). However, ovariectomy in GH-insufficient dwarf rats did not significantly alter body weight gain (Gevers et al. 1995), suggesting that at least in female rats gonadal steroids may affect growth by altering $\mathrm{GH}$ actions.

In male rats, alterations of gonadal steroids have not produced consistent results. Body weight gain was attenuated in some studies (Siddiqui et al. 1989, Vanderschueren et al. 1994), but not in others (Jansson et al. 1985, Handelsman et al. 1987). Circulating IGF-I levels and hepatic GH binding either were increased (Handelsman et al. 1987) or unchanged (Siddiqui et al. 1989, Vanderschueren et al. 1994). Reasons for these inconsistencies are not clear, but aspects of growth related by gonadal steroids might be more sensitive to estrogens than to androgens.

In addition, the perinatal hormonal milieu might influence somatic growth and the somatotropic axis during 
later life. In male rats prepubertal castration did not reduce body weight gain as much as neonatal castration, and neonatal administration of testosterone clearly affected somatic growth (Jansson et al. 1985). Furthermore, a previous study has shown that prepubertal castration enhanced serum IGF-I concentrations, while neonatal administration of gonadotropin-releasing hormone $(\mathrm{GnRH})$ antagonist abolished this pubertal rise of IGF-I (Handelsman et al. 1987). Thus, one suspects that gonadotropin elevation induced by gonadectomy might have contributed to the IGF-I rise during puberty. Accordingly, sex steroids may participate importantly in growth and in regulation of the somatotropic axis both during puberty and during early postnatal life.

We sought to clarify the mechanisms underlying the effects of prepubertal manipulation of gonadal steroids on the somatotropic axis by studying completely GH-deficient rats. The dwarf rats used in previous investigations (Gevers et al. 1995) were only partially $\mathrm{GH}$-deficient, with residual $\mathrm{GH}$ in the circulation representing approximately $10 \%$ of concentrations in normal rats (Carmignac \& Robinson 1990). Animals used in the present study were completely deficient in $\mathrm{GH}$, as confirmed by abnormal splicing of the $\mathrm{GH}$ gene and absence of GH products in the pituitary (Nogami et al. 1989, Takeuchi et al. 1990). The present study also characterizes prepubertal gonadal suppression with $\mathrm{GnRH}$ agonistic analogue $(\mathrm{GnRHa})$ since early postnatal life. In this manner, potentially confounding effects from elevated gonadotropins and imprinting effects of neonatal androgens on the somatotropic axis can be minimized.

\section{Materials and Methods}

\section{Study protocol}

The spontaneous dwarf rats were generously provided by Roussel Morishita Research Laboratories (Shiga, Japan). This animal has an autosomal recessive mutation in the $\mathrm{GH}$ gene resulting in complete absence of the $\mathrm{GH}$ protein while prolactin-, adrenocorticotropin-, thyroidstimulating hormone- and luteinizing hormone-producing pituitary cells are unaffected (Nogami et al. 1989, Takeuchi et al. 1990). Thus, this unique model of dwarfism shows isolated, complete GH deficiency (GHD). Adult Sprague-Dawley rats were purchased from CLEA JAPAN INC. (Shizuoka, Japan) and used as control animals. GHD rats and Sprague-Dawley rats approximately 15 weeks old were crossed to obtain GHD and Sprague-Dawley newborn rats for the study. Pups were assigned randomly to either GnRHa or saline treatment groups.

Treatment groups for the first experiment were as follows: male GHD rats treated with GnRHa $(n=6)$; male GHD rats treated with saline $(n=6)$; female GHD rats treated with GnRHa $(n=5)$; female GHD rats treated with saline $(n=5)$; male Sprague-Dawley rats treated with GnRHa $(n=5)$; male Sprague-Dawley rats treated with saline $(n=6)$; female Sprague-Dawley rats treated with GnRHa $(n=4)$; female Sprague-Dawley rats treated with saline $(n=4)$. The first dose of GnRHa or saline was given within $48 \mathrm{~h}$ after birth, after which GnRHa or saline injections were repeated every 3 weeks. The GnRHa, leuprolide acetate depot, was kindly provided by Takeda Chemical Industries Ltd (Tokyo, Japan). The dose of GnRHa (2 mg/kg, s.c.) was determined according to a previous study (Sudo et al. 1991), where this dosage produced marked gonadal suppression. Animals were weighed weekly to measure somatic growth. At the end of the study at age 15 weeks, rats were killed by cardiac exsanguination under ether anesthesia. Blood sampling and tissue sampling including liver and testis were performed. The wet weight of the testis was measured. Livers were frozen immediately on liquid nitrogen. Serum and livers were stored at $-20^{\circ} \mathrm{C}$ until assayed.

In the second experiment, Sprague-Dawley rats were treated with GnRHa (male, $n=3$; female, $n=4$ ) or saline (male, $n=4$; female $n=5$ ) under the same treatment regimen as described for the first experiment, and serial tail vein blood sampling was performed every 3 weeks to evaluate serum IGF-I levels.

All rats were housed in animal facilities with $12 \mathrm{~h}$ light : $12 \mathrm{~h}$ darkness and an ambient temperature of $25^{\circ} \mathrm{C}$. A block rodent diet (CA-1; CLEA JAPAN INC.) and tap water were provided and animals were allowed to feed and drink ad libitum. The protocol was approved by the Animal Studies Committee of the Tohoku University School of Medicine.

\section{Hormonal assays}

Serum levels of testosterone and $\mathrm{E}_{2}$ were determined with commercially available RIA kits (DPC Japan, Tokyo). Respective minimum detectable values for testosterone and $\mathrm{E}_{2}$ were $5 \mathrm{ng} / \mathrm{dl}$ and $5 \mathrm{pg} / \mathrm{ml}$. Serum IGF-I concentrations were determined by a double antibody RIA using a rabbit antiserum to rh-met IGF-I (878/4) at a final titer of 1:250 000 following extraction of plasma binding proteins by an acid-ethanol cryo-precipitation technique (Breier et al. 1991). Excess insulin-like growth factor-II (IGF-II) was added to the assay buffer in order to remove the interfering effects of residual IGF binding proteins. This assay has been extensively validated for rat serum (Breier et al. 1994). Intra- and interassay coefficients of variation respectively were $5.9 \%$ and $8.5 \%$ for testosterone, $4 \cdot 4 \%$ and $4 \cdot 2 \%$ for $\mathrm{E}_{2}$, and $4 \cdot 5 \%$ and $7 \cdot 2 \%$ for IGF-I.

\section{Hepatic GH binding analysis}

Hepatic GH binding assays were performed as described previously (Breier et al. 1988) and validated for rat liver (Singh et al. 1992, Gargosky et al. 1995, Ambler et al. 
1996, Butler et al. 1996). In brief, microsomal membranes were prepared as follows. Liver tissue was thawed at $4{ }^{\circ} \mathrm{C}$, cut into small pieces $(\sim 1 \mathrm{~g})$, and washed in cold $\left(4^{\circ} \mathrm{C}\right)$ $0 \cdot 3 \mathrm{M}$ sucrose. The tissue was then weighed and homogenized $(1: 3 \mathrm{wt} / \mathrm{vol})$ in $0 \cdot 3 \mathrm{M}$ sucrose containing aprotinin (106 kallikrein inhibitor units [KIU]/1; Trasylol, Bayer Pharmaceuticals, Botany, Australia). The homogenate was centrifuged at $1500 \mathrm{~g}$ for $20 \mathrm{~min}$ at $4{ }^{\circ} \mathrm{C}$, and the resulting supernatants were centrifuged sequentially at $15000 \boldsymbol{g}$ for $20 \mathrm{~min}$ and $100000 \boldsymbol{g}$ for $90 \mathrm{~min}$ at $4{ }^{\circ} \mathrm{C}$. The $100000 \boldsymbol{g}$ pellet was incubated with $4 \mathrm{M} \mathrm{MgCl}_{2}(1: 2$ wt/vol ratio of initial liver weight) for $20 \mathrm{~min}$ at $4{ }^{\circ} \mathrm{C}$ to remove endogenously bound ligands (Breier et al. 1988). The preparation was then centrifuged at $48500 \mathrm{~g}$ for $60 \mathrm{~min}$ at $4{ }^{\circ} \mathrm{C}$, and the resulting pellet was suspended in $0 \cdot 025 \mathrm{M}$ HEPES buffer, $\mathrm{pH} 7 \cdot 6$, and centrifuged again at $48500 \mathrm{~g}$ for $20 \mathrm{~min}$ at $4^{\circ} \mathrm{C}$. Aliquots of the final pellet were resuspended in cold $0 \cdot 25 \mathrm{M}$ HEPES buffer, $\mathrm{pH} 7 \cdot 6$, containing aprotinin $106 \mathrm{KIU} / \mathrm{l}$ at a ratio of $1 \mathrm{ml}$ buffer/g wet wt initial liver tissue and frozen in aliquots at $-20{ }^{\circ} \mathrm{C}$ until further analysis. Binding analysis was performed in triplicate using $50 \mu \mathrm{l}$ of membrane preparation (the equivalent of $50 \mathrm{mg}$ initial wet liver weight) per tube. The membrane preparations were incubated with approx. 30000 c.p.m. of ${ }^{125} \mathrm{I}-\mathrm{bGH}$ (batch \#PR003, Dr W Baumbach, American Cyanamide Co, Princeton, NJ, USA) at a final incubation volume of $0.5 \mathrm{ml}$ for $20 \mathrm{~h}$. Non-specific binding was determined by addition of excess of unlabeled bGH (1000 ng/tube). Incubation was terminated by adding $3 \mathrm{ml}$ of ice-cold $0.025 \mathrm{~mol} / 1$ TRIS, $0 \cdot 01 \mathrm{~mol} / 1 \mathrm{CaCl}_{2}$ buffer, $\mathrm{pH} 7 \cdot 6$. Bound and free hormone were separated by centrifugation at $3000 \mathrm{~g}$ for $45 \mathrm{~min}$ at $4{ }^{\circ} \mathrm{C}$. Equilibrium was reached under these conditions and specific binding was completely reversible by the addition of excess of the appropriate ligand. The intra- and interassay coefficients of variation were $5 \cdot 7 \%$ and $9 \cdot 8 \%$ respectively. Protein concentrations of the membrane preparations for individual animals were determined by a modified Lowry method (Singh et al. 1992), and specific binding has been corrected for protein concentration.

\section{Data analysis}

Serial body weight data were assessed by ANOVA for two-factor repeated measurements, and other data were analyzed by ANOVA for factorial measurements, both followed by Fisher's protected least significant difference method with correction for multiple comparisons as appropriate. Statistical significance was accepted at $P<0 \cdot 05$. All values are expressed as the mean \pm s.D.

\section{Results}

Body weight of male Sprague-Dawley rats was significantly greater than female $(P<0 \cdot 01)$, and the males were
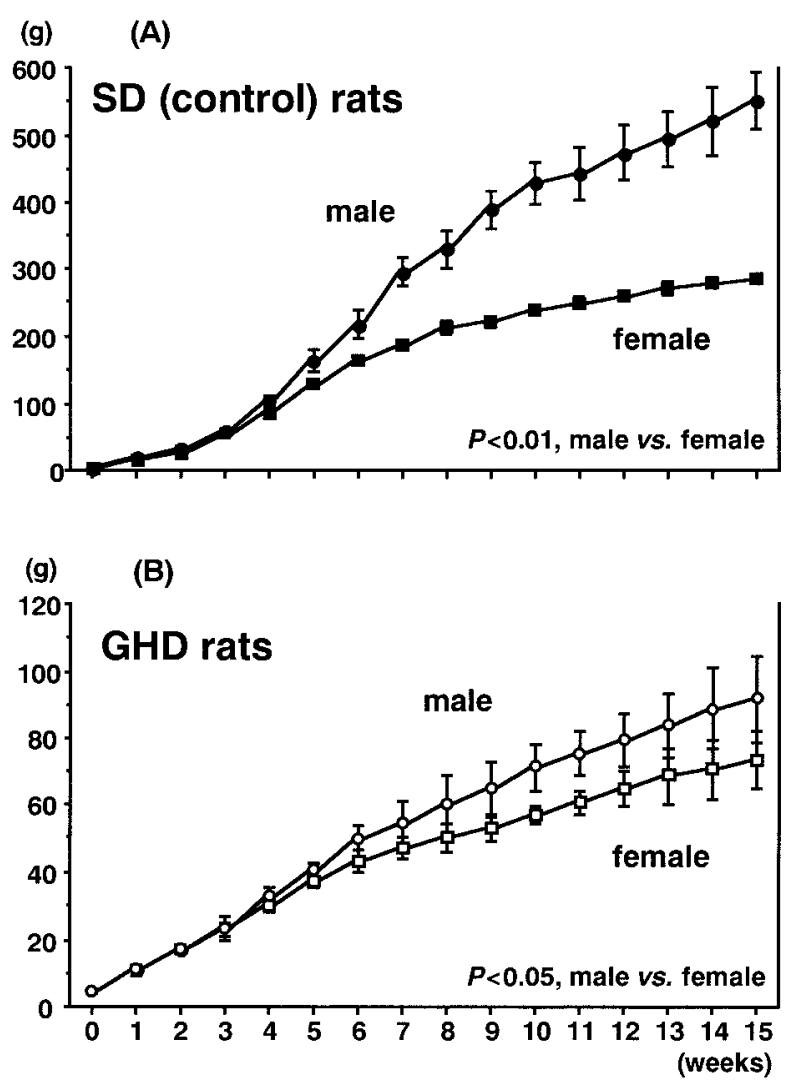

Figure 1 Mean body weight ( \pm S.D.) in Sprague-Dawley (control) rats (A) and GHD rats (B) given saline injections. Male Sprague-Dawley (control) rats $(\mathbf{0})$, female Sprague-Dawley (control) rats $(\mathbf{\square})$, male GHD rats $(\bigcirc)$, and female GHD rats ( $\square$ ) are depicted. SD, Sprague-Dawley.

twice as heavy as females at 15 weeks (Fig. 1A). While male GHD rats also weighed significantly more than females $(P<0 \cdot 05)$, sex difference in body weight was small (only 25\% heavier at 15 weeks, Fig. 1B). Serum IGF-I concentrations were higher, and hepatic GH binding was lower, in male Sprague-Dawley rats than in females, while these sex differences were not observed in GHD rats (Fig. 2). Circulating testosterone and $\mathrm{E}_{2}$ levels at 15 weeks were lower in GHD than in Sprague-Dawley rats, although the differences did not reach significance (GHD vs Sprague-Dawley for testosterone, $154 \cdot 1 \pm 83 \cdot 5$ vs $260 \cdot 7 \pm 152 \cdot 4 \mathrm{ng} / \mathrm{dl}, P=0 \cdot 07$; for $\mathrm{E}_{2}, 14 \cdot 0 \pm 5 \cdot 9$ vs $25 \cdot 2 \pm 12 \cdot 9 \mathrm{pg} / \mathrm{ml}, P=0 \cdot 06)$.

GnRHa treatment achieved gonadal suppression as evidenced by decreased serum concentrations of testosterone (control, $260 \cdot 7 \pm 152 \cdot 4$ vs $59 \cdot 1 \pm 23 \cdot 3 \mathrm{ng} / \mathrm{dl}, P<0 \cdot 01$; GHD, $154 \cdot 1 \pm 83.5$ vs $48 \cdot 9 \pm 23 \cdot 1 \mathrm{ng} / \mathrm{dl}, P<0 \cdot 01)$ or $\mathrm{E}_{2}$ (control, $25 \cdot 2 \pm 12 \cdot 9$ vs $5 \cdot 3 \pm 2 \cdot 0 \mathrm{pg} / \mathrm{ml}, P<0 \cdot 05$; GHD, $14 \cdot 0 \pm 5 \cdot 9$ vs $5 \cdot 2 \pm 0 \cdot 5 \mathrm{pg} / \mathrm{ml}, P<0 \cdot 05)$ and reduced testicular wet weight (control, $1.89 \pm 0.13$ vs $1.22 \pm 0.06 \mathrm{~g}$, $P<0 \cdot 01$; GHD, $0 \cdot 70 \pm 0.06$ vs $0 \cdot 46 \pm 0.03 \mathrm{~g}, P<0 \cdot 01)$ or 
(A)

\section{SD (control) rats}

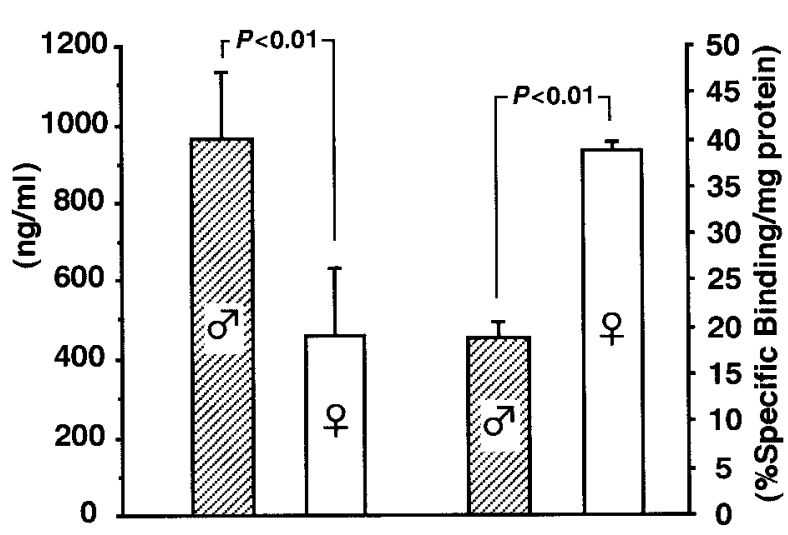

(B)

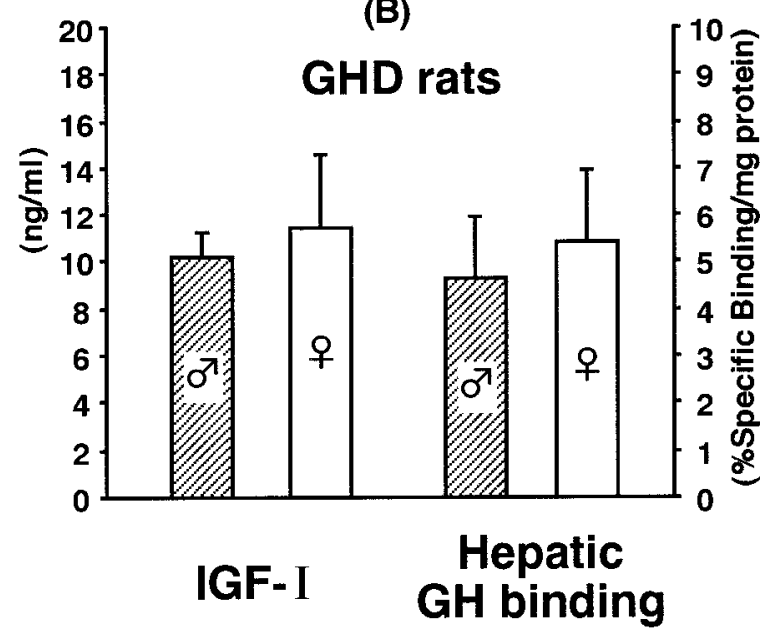

Figure 2 Mean circulating IGF-I levels and hepatic GH binding ( \pm S.D.) at 15 weeks in Sprague-Dawley (control) rats $(A)$ and GHD rats (B). Males, hatched columns; females, open columns; SD, Sprague-Dawley.

impaired development of the ovaries and uterus. Treatment with GnRHa did not significantly alter body weight, serum IGF-I levels or hepatic GH binding in either male Sprague-Dawley or male GHD rats (Fig. 3). However, body weight was significantly greater and hepatic GH binding was significantly lower in GnRHa-treated female Sprague-Dawley control rats $(P<0 \cdot 01)$. However, in GHD female rats body weight and hepatic GH binding were not affected by GnRHa treatment. GnRHa treatment did not change circulating IGF-I levels in either female Sprague-Dawley or female GHD rats (Fig. 4). In addition, serial IGF-I measurement from the second experiment revealed that IGF-I levels were not affected by the GnRHa treatment at any time points before 15 weeks
(A)

SD (control) rats

$\sigma^{7}$

(B)

GHD rats

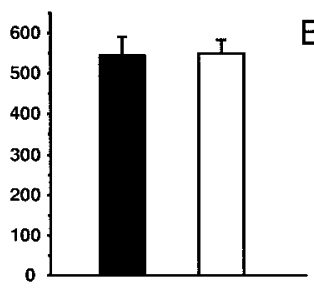

Body weight

(g)
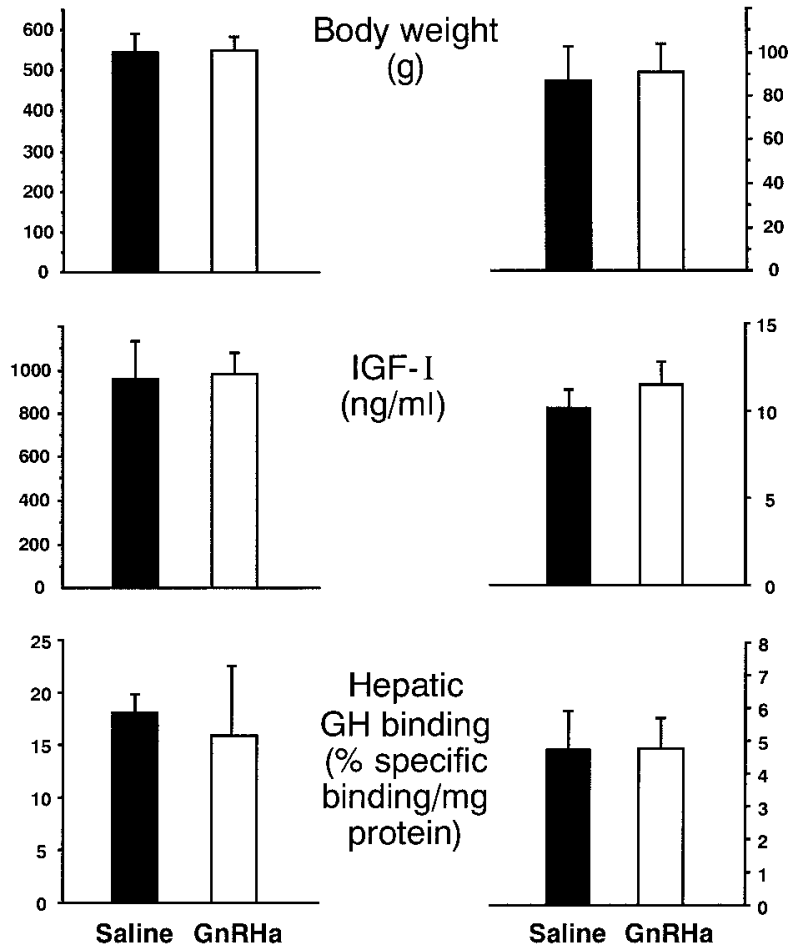

Figure 3 Mean body weight (upper panels), circulating IGF-I levels (middle) and hepatic $\mathrm{GH}$ binding (lower) at 15 weeks in male Sprague-Dawley (control) rats (A) and GHD rats (B). Rats were treated either with saline (filled columns) or GnRHa (open columns). Values are \pm S.D. SD, Sprague-Dawley.

of age in both male and female Sprague-Dawley control rats (Fig. 5).

\section{Discussion}

Three major mechanisms have been proposed for the effects of gonadal steroids on growth and the somatotropic axes: mediation via GH secretory status (indirect effects); direct effects such as on local growth factors; and alteration of $\mathrm{GH}$ responsiveness by gonadal steroids. GH secretory status is known to be changed by modulation of gonadal steroids in rats as well as in humans (Jansson et al. 1985, Wehrenberg \& Guistina 1992). In a study of dwarf rats, Gevers et al. reported that gonadectomy suppressed body weight gain in male rats but had no effect in female rats (Gevers et al. 1995). The authors suggested that androgens had such a direct action while estrogens altered GH secretion to affect growth. However, the same authors later reported a study where GnRHa had little effect on $\mathrm{GH}$ secretion, and postulated that growth enhancement 
(A)

SD (control) rats

오

(B)
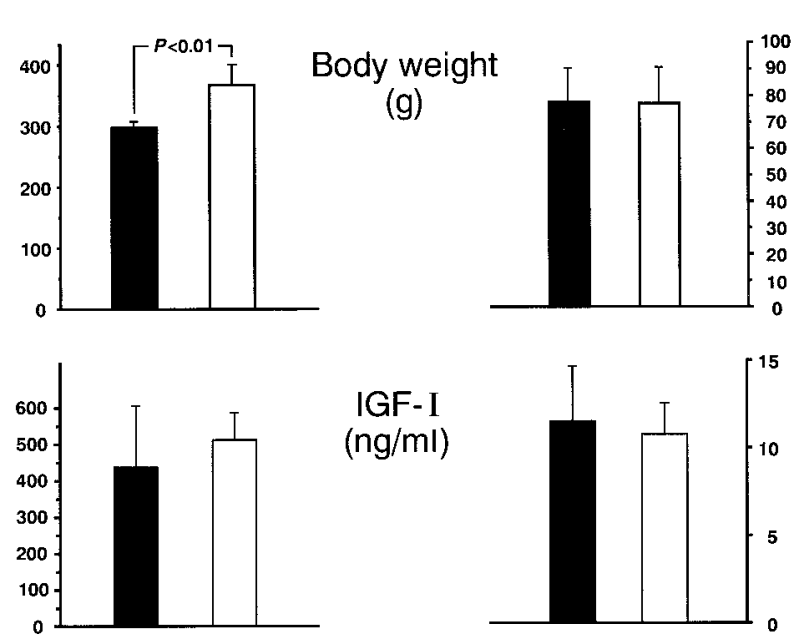

IGF-I $(\mathrm{ng} / \mathrm{ml})$
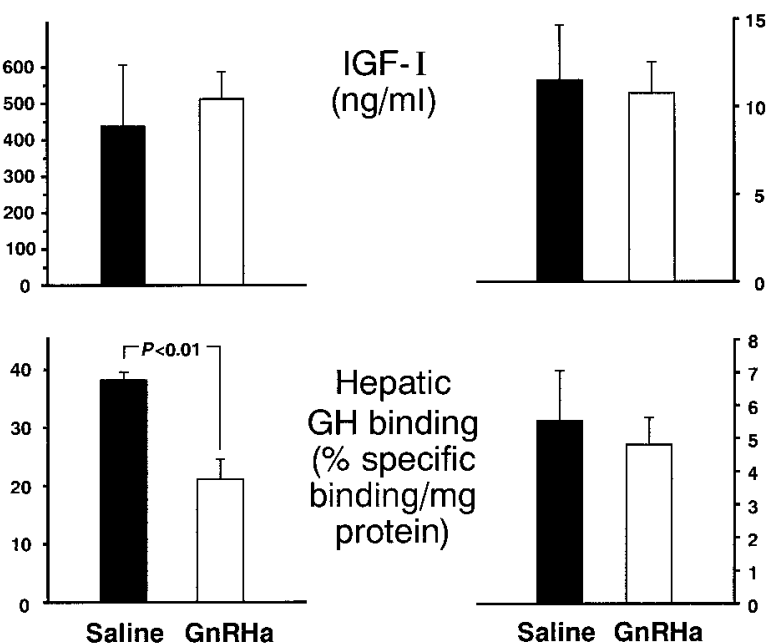

Figure 4 Mean body weight (upper panels), circulating IGF-I levels (middle), and hepatic GH binding (lower) at 15 weeks in female Sprague-Dawley (control) rats (A) and GHD rats (B). Rats were treated either with saline (filled columns) or GnRHa (open columns). Values are \pm S.D. SD, Sprague-Dawley.

by GnRHa was due to a reduction of direct inhibition by estrogens (Gevers et al. 1998). In addition, an earlier study has shown that $\mathrm{E}_{2}$ administration suppressed somatic growth in ovariectomized, hypophysectomized female rats, suggesting a direct effect of estrogens (Jansson et al. 1983). Whether the effects of gonadal steroids on growth are mediated through the somatotropic axis therefore is not clear. Previous studies have used GH deficient rats with residual $\mathrm{GH}$ as high as $10 \%$ of normal. Other studies have used hypophysectomized rats, in which multiple pituitary hormones were insufficient. In the present study, we used the spontaneous dwarf rat, which has a splicing mutation in the GH gene (Takeuchi et al. 1990). Absence of GH protein in the pituitaries of these animals has been confirmed (Nogami et al. 1989). This animal model, then, showed isolated complete GH deficiency, and modulation of gonadal steroids could not alter GH secretory status as was possible in GH-insufficient dwarf rat models. Therefore, direct effects of gonadal steroid modulation on growth can be clarified in this model.

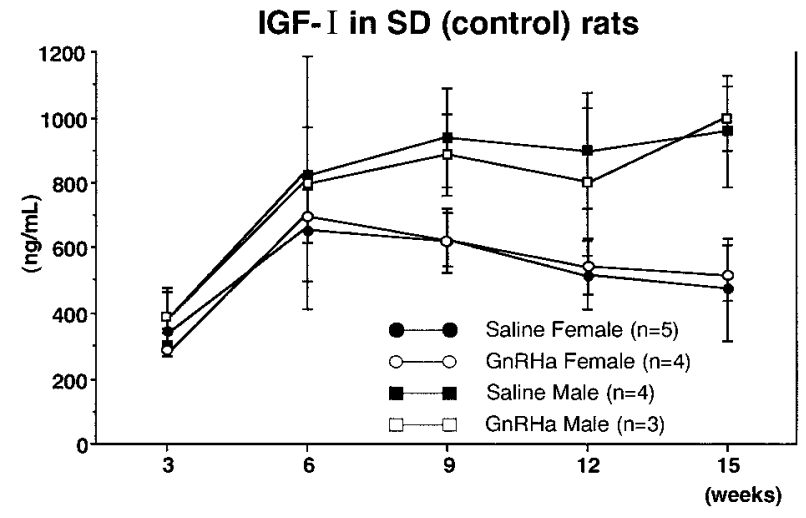

Figure 5 Mean circulating IGF-I levels ( \pm S.D.) in Sprague-Dawley (control) rats. Saline-treated male rats $(\boldsymbol{\square})$, GnRHa-treated male rats $(\square)$, saline-treated female rats $(\bullet)$, and GnRHa-treated female rats $(\bigcirc)$ are depicted. SD, Sprague-Dawley.

Our study suggests that sexual dimorphism in circulating IGF-I levels and hepatic GH receptor concentration appears to be GH-dependent. In Sprague-Dawley control rats marked sexual dimorphism was seen in circulating IGF-I levels and hepatic GH binding, while they did not differ between sexes in GHD rats. In addition, although our male GHD rats were significantly heavier than females as originally reported (Okuma \& Kawashima 1980), the difference was relatively small, only $25 \%$ at 15 weeks. In contrast, male Sprague-Dawley rats weighed twice as much as female Sprague-Dawley rats. These results suggest that the sexual dimorphism seen in control rats may be mediated mainly by sexually dimorphic GH secretion and action. Other factors independent of $\mathrm{GH}$, such as direct actions of sex steroids, would have only minor effects on sexually dimorphic postnatal somatic growth in rats.

As shown in the present study, suppression of gonadal function by GnRHa did not alter body weight gain in male or female GHD rats. In Sprague-Dawley males, GnRHa treatment did not alter body weight. Orchiectomy generally inhibits body weight gain, but it was also reported that prepubertal orchiectomy had little effect on growth (Jansson et al. 1985). The effect of orchiectomy on somatic growth appears to be smaller than that of ovariectomy; reduction of body weight gain in orchiectomized rats was less than $10 \%$, while in female ovariectomized rats, body weight increased by $30 \%$ (Gevers et al. 1998). Moreover, gonadal suppression induced by GnRHa was not complete in our study. Testicular weight was reduced by only $50 \%$ in SpragueDawley rats treated with GnRHa despite testosterone levels being markedly reduced. Thus, another reason for a lack of GnRHa effect on body weight in male rats may be incomplete gonadal suppression. On the other hand, in female Sprague-Dawley rats, GnRHa-induced ovarian hypofunction augmented body weight gain as repeatedly reported in ovariectomized rats (Jansson et al. 1985, 
Wehrenberg \& Guistina 1992). However, GnRHa did not have any effect in female GHD rats. This suggests that the effects of gonadal steroids in female rats are mediated primarily by GH. Our study also has demonstrated that hepatic GH binding was not altered in tissues from GHD rats despite reduced estrogens, which indicates that modulation of hepatic $\mathrm{GH}$ binding by estrogens also requires the presence of $\mathrm{GH}$.

Circulating IGF-I levels were not altered by GnRHa treatment in either sex or in either strain of rats. To examine whether GnRHa treatment can change IGF-I levels before 15 weeks of age, serum concentrations of IGF-I were measured every 3 weeks in Sprague-Dawley rats in the second experiment. The results indicated that, in both male and female rats, IGF-I levels were not different between the treatment groups. Since GnRHa did not affect growth in male rats, lack of effects on hepatic GH binding and unchanged serum IGF-I concentrations were not surprising. However, reduction of estrogens by GnRHa resulted in enhanced growth in control Sprague-Dawley rats as outlined above; this augmentation was accompanied by reduced hepatic GH binding and unchanged serum IGF-I concentrations. Studies of ovariectomized rats also showed a reduction in hepatic GH binding but circulating IGF-I levels were increased (Handelsman et al. 1987, Gevers et al. 1995, Borski et al. 1996). Augmented IGF-I concentrations resulting from elimination of estrogens have been linked to enhanced growth, but no analogous relationship has been observed in male rats. Unaltered levels of serum IGF-I in our study might be related to inhibited gonadotropin levels, since elimination of estrogens was accomplished by ovariectomy in other studies. Alternatively, suppression of gonadal function during early postnatal life might have abolished the later rise in IGF-I. An earlier study has demonstrated that neonatal administration of a GnRH antagonist abolished the pubertal rise of IGF-I (Handelsman et al. 1987). Thus, early postnatal inhibition of gonadotropins can affect IGF-I levels at puberty.

In summary, an increase in body weight seen in female control rats with GnRHa treatment was not observed in GHD rats. This suggests that the GH-induced somatic growth in rats is modulated by estrogens but not androgens. Although the present study did not determine whether androgens have any direct effects on growth, possible small direct effects of androgens on body weight as previously suggested (Gevers et al. 1995) may explain a slightly greater body weight in male GHD rats than females. Reasons for lack of change in IGF-I levels with suppression of gonadal function by $\mathrm{GnRHa}$ are unclear. The sexual difference in body size and its modulation by estrogens seem to be independent of circulating IGF-I levels suggesting non-endocrine IGF-I-mediated mechanisms. The complex interrelationship between the gonadotropic and the somatotropic axes requires further study to clarify details of mechanisms and interactions among the various influences.

\section{Acknowledgements}

We acknowledge Ms Sachiko Sato and Mr Andrzej Surus for their excellent technical assistance. This work was supported by grants from the Ministry of Education, Science and Culture, Japan, and from the Health Research Council, New Zealand.

\section{References}

Ambler GR, Butler AB, Padmanathan J, Breier BH \& Gluckman PD 1996 The effects of octreotide on growth hormone $(\mathrm{GH})$ receptor and insulin-like growth factor-I expression in the GH-deficient dwarf rat. Journal of Endocrinology 149 223-231.

Borski R, Tsai W, Demott-Friberg R \& Barkan A 1996 Regulation of somatic growth and the somatotropic axis by gonadal steroids: primary effect on insulin-like growth factor I gene expression and secretion. Endocrinology 137 3253-3259.

Breier BH, Gluckman PD \& Bass JJ 1988 The somatotrophic axis in young steers: influence of nutritional status and oestradiol-17 $\beta$ on hepatic high- and low-affinity somatotrophic binding sites. Journal of Endocrinology 116 169-177.

Breier BH, Gallaher BW \& Gluckman PD 1991 Radioimmunoassay for insulin-like growth factor-I: solutions to some potential problems and pitfalls. Journal of Endocrinology 128 347-357.

Breier BH, Ambler GR, Saurwein H, Surus A \& Gluckman PD 1994 The induction of hepatic somatotropic receptors after birth in sheep is dependent on parturition associated mechanisms. Journal of Endocrinology 141 101-108.

Butler AA, Funk B, Breier BH, LeRoith D, Roberts CT Jr \& Gluckman PD 1996 Growth hormone (GH) status regulates GH receptor and $\mathrm{GH}$ binding protein $\mathrm{mRNA}$ in a tissue- and transcript-specific manner but has no effect on insulin-like growth factor-1 receptor mRNA in the rat. Journal of Molecular and Cellular Endocrinology 116 181-189.

Carlsson L, Eriksson E, Seeman H \& Jansson J 1987 Oestradiol increases baseline growth hormone levels in the male rat: possible direct action on the pituitary. Acta Physiologica Scandinavia 129 393-399.

Carmignac DF \& Robinson ICAF 1990 Growth hormone (GH) secretion in the dwarf rat: release, clearance and responsiveness to GH-releasing factor and somatostatin. Journal of Endocrinology 127 69-75.

Carmignac D, Robinson I, Enberg B \& Norstedt G 1993 Growth hormone receptor regulation in growth hormone-deficient dwarf rats. Journal of Endocrinology 138 267-274.

Gargosky SE, Breier BH, Broski R, Mulcahy J \& Barnard R 1995 Upregulation of $\mathrm{GH}$ receptor and $\mathrm{GH}$ binding protein during pregnancy in the GH-deficient rat. Endocrine 3 813-817.

Gevers EF, Wit JM \& Robinson ICAF 1995 Effect of gonadectomy on growth and $\mathrm{GH}$ responsiveness in dwarf rats. Journal of Endocrinology 145 69-79.

Gevers EF, Wit JM \& Robinson ICAF 1998 Effects of long-term gonadotropin-releasing hormone analog treatment on growth, growth hormone $(\mathrm{GH})$ secretion, $\mathrm{GH}$ receptors, and GH-binding protein in the rats. Pediatric Research 43 111-120.

Handelsman DJ, Spaliviero JA, Scott CD \& Baxter RC 1987 Hormonal regulation of the peripubertal surge of insulin-like growth factor-I in the rat. Endocrinology 120 491-496.

Jansson J, Eden S \& Isaksson O 1983 Site of action of testosterone and estradiol on longitudinal bone growth. American Journal of Physiology 244 E135-E140.

Jansson JO, Eden S \& Isaksson O 1985 Sexual dimorphism in the control of growth hormone secretion. Endocrine Reviews 6 128-150. 
Nogami H, Takeuchi T, Suzuki K, Okuma S \& Ishikawa H 1989 Studies on prolactin and growth hormone gene expression in the pituitary gland of spontaneous dwarf rats. Endocrinology 125 964-970.

Okuma S \& Kawashima S 1980 Spontaneous dwarf rat. Experimental Animals 29 301-303.

Siddiqui RA, McCutcheon NS, Mackenzie DDS, Blair HT, Ormsby JE, Gluckman PD \& Breier BH 1989 Role of testosterone in regulating the growth of mice from lines selected for low vs high plasma insulin-like growth factor-I concentration. Acta Endocrinologica 121 686-690.

Singh K, Ambler G, Breier BH, Klempt M \& Gluckman P 1992 Ovine placental lactogen is a potent somatogen in the growth hormone $(\mathrm{GH})$-deficient rat: comparison of somatogenic activity with bovine GH. Endocrinology 130 2758-2766.

Sudo K, Shiota K, Masaki T \& Fujita T 1991 Effects of TAP-144-SR, a sustained-release formulation of a potent $\mathrm{GnRH}$ agonist, on experimental endometriosis in the rat. Endocrinologica Japonica 38 $39-45$.
Takeuchi T, Suzuki H, Sakurai S, Nogami H, Okuma S \& Ishikawa H 1990 Molecular mechanism of growth hormone (GH) deficiency in the spontaneous dwarf rat: detection of abnormal splicing of GH messenger ribonucleic acid by the polymerase chain reaction. Endocrinology 126 31-38.

Vanderschueren D, Van Herck E, Geusens P, Suiker A, Visser W, Chung K \& Bouillon R 1994 Androgen resistance and deficiency have different effects on the growing skeleton of the rat. Calcified Tissue International 55 198-203.

Wehrenberg WB \& Giustina A 1992 Mechanisms and pathways of gonadal steroid modulation of growth hormone secretion. Endocrine Reviews 13 299-308.

Received 12 July 1999

Revised manuscript received 6 December 1999

Accepted 29 March 2000 